\title{
DNA-hypomethylating agent, 5 '-azacytidine, induces cyclooxygenase-2 expression via the PI3-kinase/Akt and extracellular signal-regulated kinase-1/2 pathways in human HT1080 fibrosarcoma cells
}

\author{
SEON-MI YU and SONG-JA KIM
}

Department of Biological Sciences, College of Natural Sciences, Kongju National University, Gongju 182, Republic of Korea

Received June 8,2015; Accepted July 17, 2015

DOI: $10.3892 /$ ijo.2015.3110

\begin{abstract}
The cytosine analogue 5'-azacytidine (5'-aza) induces DNA hypomethylation by inhibiting DNA methyltransferase. In clinical trials, 5'-aza is widely used in epigenetic anticancer treatments. Accumulated evidence shows that cyclooxygenase-2 (COX-2) is overexpressed in various cancers, indicating that it may play a critical role in carcinogenesis. However, few studies have been performed to explore the molecular mechanism underlying the increased COX-2 expression. Therefore, we tested the hypothesis that 5'-aza regulates COX-2 expression and prostaglandin $\mathrm{E}_{2}\left(\mathrm{PGE}_{2}\right)$ production. The human fibrosarcoma cell line HT1080, was treated with various concentrations of 5'-aza for different time periods. Protein expressions of COX-2, DNA (cytosine-5)-methyltransferase 1 (DNMT1), pAkt, Akt, extracellular signal-regulated kinase (ERK), and phosphorylated ERK (pERK) were determined using western blot analysis, and COX-2 mRNA expression was determined using RT-PCR. $\mathrm{PGE}_{2}$ production was evaluated using the $\mathrm{PGE}_{2}$ assay kit. The localization and expression of COX-2 were determined using immunofluorescence staining. Treatment with 5'-aza induces protein and mRNA expression of COX-2. We also observed that 5'-aza-induced COX-2 expression and $\mathrm{PGE}_{2}$ production were inhibited by $\mathrm{S}$-adenosylmethionine (SAM), a methyl donor. Treatment with 5'-aza phosphorylates PI3-kinase/ Akt and ERK-1/2; inhibition of these pathways by LY294002, an inhibitor of PI3-kinase/Akt, or PD98059, an inhibitor of ERK-1/2, respectively, prevents 5'-aza-induced COX-2 expression and $\mathrm{PGE}_{2}$ production. Overall, these observations indicate that the hypomethylating agent 5'-aza modulates COX-2 expres-
\end{abstract}

Correspondence to: Dr Song-Ja Kim, Department of Biological Sciences, Kongju National University, 56 Daehakro, Gongju 314-701, Republic of Korea

E-mail: ksj85@kongju.ac.kr

Key words: 5'-azacytidine, cyclooxygenase-2, human fibrosarcoma cells, PI3-kinase/Akt, extracellular signal-regulated kinase-1/2 sion via the PI3-kinase/Akt and ERK-1/2 pathways in human HT1080 fibrosarcoma cells.

\section{Introduction}

Fibrosarcoma is a malignant cancer that originates in the connective tissue found at the ends of bones of the legs or arms, and then spreads to the surrounding soft tissues. Soft tissues include joint tissue, blood vessels, fat, muscles, tendons, and fibrous tissue. Although fibrosarcoma-related morbidity is rare, patient survival rates are low (1).

During the last few decades, epigenetics has been one of the emerging fields in cancer research (2). Epigenetics affects the transcription of cells, thereby regulating gene expression. Abnormal epigenetic changes can have adverse effects on the organism. Methylation of cytosine-phosphate-guanine ( $\mathrm{CpG})$ islands in the promoter region of a gene has now been strongly linked to gene silencing.

DNA methylation is regulated by DNA methyltransferases (DNMT1, DNMT3A and DNMT3B), which catalyze the transfer of a methyl group from S-adenosyl-1-methionine (SAM) to the cytosine of a CpG dinucleotide (adjacent within a single DNA strand), immediately following replication (3).

DNMTs are classified as maintenance or de novo methyltransferases. Maintenance DNMT1 binds methyl groups to methylated DNA during replication, whereas de novo DNMT3A and DNMT3B add methyl groups to CpG dinucleotides of unmethylated DNA. Previous reports have shown that some anticancer cascades abnormally activate the DNMT1, enzyme that maintains the DNA methylation pattern (3).

When the levels of DNMT1 decrease, as is the case following azacytidine or decitabine treatment, daughter strands are less likely to undergo maintenance to restore full methylation; thus, with each replication, $\mathrm{CpG}$ pairs become unmethylated, rendering their promoter regions more accessible to transcription factors.

DNA damage induced by 5'-azacytidine (5'-aza) is reversible, since the drug does not influence de novo DNMT synthesis (4-6). 5'-aza has been used clinically for treating diverse diseases such as acute myelogenous leukemia, hematological malignancies, gastrointestinal, lung, ovarian, prostate, breast, and head and neck cancers, melanoma, and malignant 
mesothelioma (7). Global hypomethylation is a hallmark of cancer (8). It was believed that global hypomethylation principally targets repetitive sequences, but some genes involved in metastasis were also previously indicated to be hypomethylated in cancers (9).

There are three major isoforms of cyclooxygenase (COX), COX-1, COX-2, and COX-3. COX-1, a constitutive isoform, plays a role in modulating physiologic activities in tissues. COX-2 is an inducible isoform of the enzyme that responds to specific stimuli such as growth factor, hormones, endotoxins, and cytokines $(10,11)$. The third isoform, COX-3, an inactive protein, is an alternative splice variant of COX-1 (12).

Overexpression of COX-2 in tumors is linked to the overproduction of the pro-inflammatory prostaglandin $\mathrm{E}_{2}\left(\mathrm{PGE}_{2}\right)$ $(13,14)$. It may also trigger the acquisition of essential cancer traits (15), including inhibition of apoptosis $(16,17)$, immunosuppression (18), continued proliferation (19), invasion (20), angiogenesis $(21,22)$, and metastasis $(23,24)$.

COX-2 is usually associated with inflammation and is markedly upregulated in various types of cancer, as well as in other diseases (25-28).

The methylation status of the COX-2 promoter was shown in several cancers, and some research showed that the transcriptional silencing of COX-2 is involved in the methylation status of the CpG pairs of the COX-2 gene $(29,30)$. However, the effects of 5'-aza on COX-2 expression in human fibrosarcoma HT-1080 cells have not been reported.

In this study, we examined whether 5'-aza regulates COX-2 expression in human fibrosarcoma HT-1080 cells. We showed that 5'-aza increases COX-2 expression and $\mathrm{PGE}_{2}$ production, and identified the signaling pathways involved in these mechanisms.

\section{Materials and methods}

Reagents and chemicals. 5'-azacytidine was purchased from Sigma-Aldrich (St. Louis, MO, USA). PD 98059 was purchased from Calbiochem (San Diego, CA, USA) and LY 294002 was purchased from Tocris (Bristol, UK). Cell culture medium and fetal bovine serum (FBS) were obtained from Invitrogen (Gaithersburg, MD, USA). PCR primers were purchased from Genotek Co., (Daejeon, Korea).

Cell culture and experimental conditions. HT1080 human fibrosarcoma cells were obtained from the Korean Cell Line Bank (KCLB, Seoul, Korea). The cell line was cultured in RPMI-1640 containing 10\% (v/v) FBS, $50 \mathrm{U} / \mathrm{ml}$ penicillin, and $50 \mu \mathrm{g} / \mathrm{ml}$ streptomycin (Sigma-Aldrich) at $37^{\circ} \mathrm{C}$ in a humidified incubator containing $5 \% \mathrm{CO}_{2}$. The medium was refreshed daily over a period of 2 days. Treatment with drugs was performed as indicated in the figure legends.

Western blot analysis. Cells were washed with PBS and lysed using RIPA buffer containing $50 \mathrm{mM}$ Tris-HCl; $\mathrm{pH} 7.4$, $150 \mathrm{mM} \mathrm{NaCl}, 1 \%$ Nonidet P-40, and $0.1 \%$ sodium dodecyl sulfate (SDS), supplemented with inhibitors for proteases and phosphatases. Then the lysates were clarified by centrifugation $\left(1,300 \mathrm{rpm}, 10 \mathrm{~min}, 4^{\circ} \mathrm{C}\right)$ and collected. Proteins were size-fractionated using SDS-PAGE and transferred to a nitrocellulose membrane (Whatman Schleicher and Schuell,
Dachen, Germany). Antibodies against DNMT-1, COX-2, pAkt, Akt, pERK, ERK, and $\beta$-actin were used (Cell Signaling Technology, Beverly, MA, USA). The nitrocellulose sheet was blocked with $5 \%$ non-fat dry milk in Tris-buffered saline for $1 \mathrm{~h}$. Proteins were detected using horseradish peroxidase (HRP)-conjugated secondary antibodies, followed by enhanced chemiluminescence (ECL). Blots were developed using an image-Quant LAS 4000 (Amersham Biosciences Corp, Piscataway, NJ, USA).

Reverse transcriptase-polymerase chain reaction (RT-PCR). HT1080 cells were collected after treatment with the indicated drugs. Total RNA was extracted using TRIzol-reagent (Invitrogen, Life Technologies, Carlsbad, CA, USA) according to the manufacturer's instructions. cDNA was synthesized using reverse-transcriptase according to the manufacturer's instructions, and was used as the template for PCR amplification. The primer sequences of COX-2 specific primer sets were as follows: COX-2 sense, 5'-TTC AAA TGA GAT TGT GGA AAA ATT GCT-3'; antisense, 5'-AGA TCA TCT CTG CCT GAG TAT CTT-3'. GAPDH, sense, 5'-CGT CTT CAC CAC CAT GGA GA-3'; antisense, 5'-CGG CCA TCA CGC CAC AGT TT-3'. GAPDH was used as a loading control. Each sample was incubated at $95^{\circ} \mathrm{C}$ for $30 \mathrm{sec}, 55^{\circ} \mathrm{C}$ for $30 \mathrm{sec}$, and $72^{\circ} \mathrm{C}$ for $30 \mathrm{sec}$ for 30 cycles. Reaction samples were then incubated for an additional $7 \mathrm{~min}$ at $72^{\circ} \mathrm{C}$ and cooled to $4^{\circ} \mathrm{C}$. PCR products were resolved on $1.2 \%$ agarose gel.

Prostaglandin E (PGE $)$ assay. Cells ( $2 \times 10^{4}$ cells/well) were seeded onto 96 -well plates. At $24 \mathrm{~h}$ after treatment, conditioned medium was harvested, and $\mathrm{PGE}_{2}$ concentrations were determined using an ELISA assay kit according to instructions supplied by the manufacturer (Assay Designs, Ann Arbor, MI, USA). Samples were assayed in triplicate in each of three independent experiments. $\mathrm{PGE}_{2}$ levels were calculated against a standard $\mathrm{PGE}_{2}$ curve.

Immunofluorescence (IF) staining. Cells were treated for $24 \mathrm{~h}$ with or without 5'-aza in the presence of inhibitor, PD 98059 or LY 294002. Cells were harvested, fixed with ice-cold $3.5 \%$ paraformaldehyde (Sigma-Aldrich) for $15 \mathrm{~min}$, and washed with ice-cold phosphate-buffered saline (PBS). Cells were then permeabilized with $0.1 \%$ Triton $\mathrm{X}-100$ for $15 \mathrm{~min}$, washed with ice-cold PBS, and stained with antibodies against COX-2. Cell nuclei were stained with 4i,6-diamidino2-phenylindol (DAPI, Molecular Probes/Invitrogen, Carlsbad, CA, USA) and were observed using a fluorescence microscope (Olympus, Tokyo, Japan) with peak excitation wavelengths at 570 and $460 \mathrm{~nm}$.

Data analysis and statistical analyses. Values are presented as the mean \pm Standard deviation (SD) of at least three independent experiments. Data were evaluated using the one-way ANOVA. $\mathrm{P}<0.05$ was considered to indicate statistically significant differences between values.

\section{Results}

This study aimed to determine whether 5'-aza regulates COX-2 expression in HT1080 cells. HT1080 cells treated with 5'-aza 
A

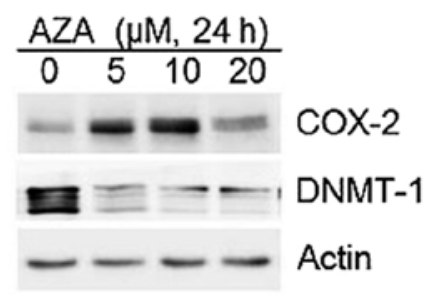

C

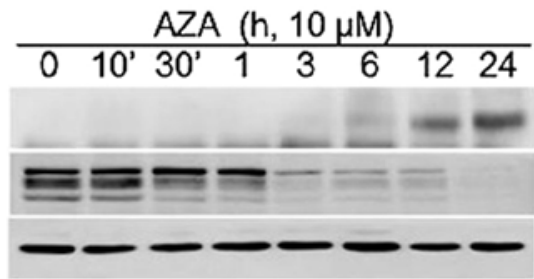

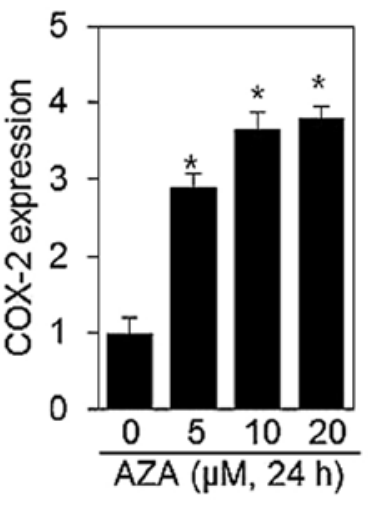

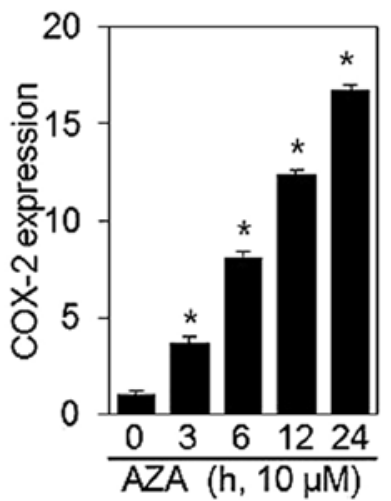

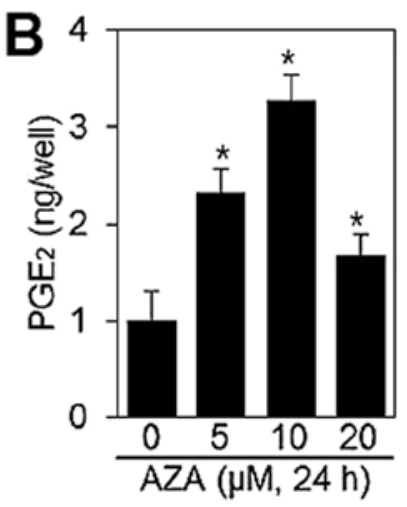

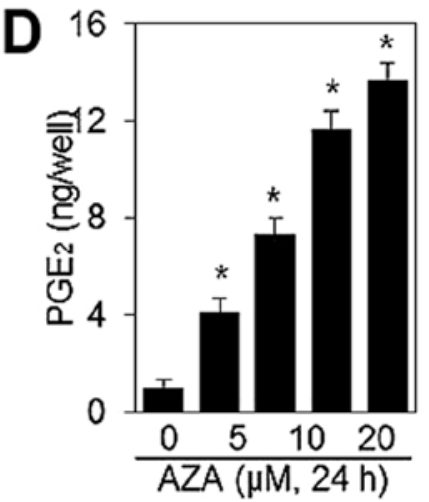

Figure 1. Treatment with 5'-aza increases COX-2 expression and $\mathrm{PGE}_{2}$ production. (A and B) Chondrocytes were treated with and without various concentrations of 5'-aza for $24 \mathrm{~h}$. (C and D) Chondrocytes were treated with and without $10 \mu \mathrm{M} 5$ '-aza for the indicated time periods. (A and C) Expression of COX-2,

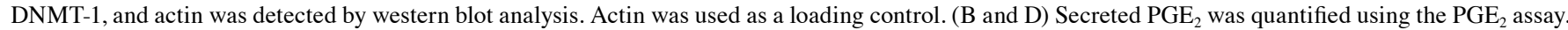
Data were given as mean $\pm \mathrm{SD}$, with three independent experiments performed in triplicate, compared with the control group: * $\mathrm{P}<0.01$.

A

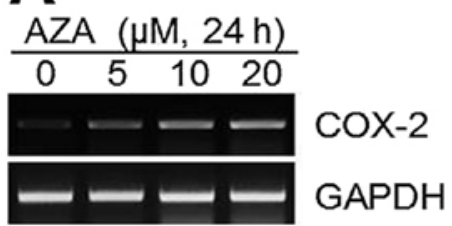

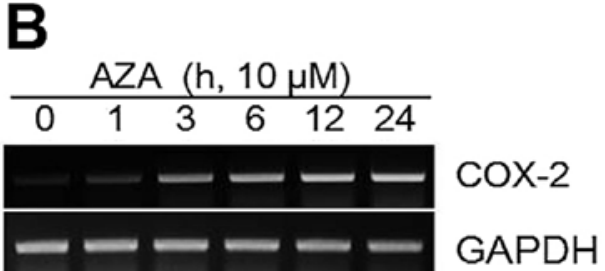

Figure 2. Treatment with 5'-aza upregulates COX-2 mRNA expression. (A) Chondrocytes were treated with and without various concentrations of 5'-aza for $24 \mathrm{~h}$. (B) Chondrocytes were treated with and without $10 \mu \mathrm{M} 5$ '-aza for the indicated time periods. (A and B) The expression level of COX-2 was determined using RT-PCR. GAPDH was used as a loading control. The data represent three similar experiments.

exhibited augmented COX-2 expression in comparison with untreated cells (Fig. 1A). A concentration-independent increase in COX-2 expression was observed (Fig. 1A). Stimulation of cells with 5'-aza markedly increased COX-2 expression, which was evident within $6 \mathrm{~h}$, and reached a maximum at $24 \mathrm{~h}$ (Fig. 1C). Densitometric evaluation of a representative western blot experiment was performed in triplicate (Fig. 1A and C, right panels).

To assess the effect of 5'-aza on COX-2 activity, we quantified the production of $\mathrm{PGE}_{2}$ in HT1080 cells untreated and treated with 5'-aza for $24 \mathrm{~h}$ (Fig. 1B and D). A significant increase in $\mathrm{PGE}_{2}$ synthesis was verified in HT1080 cells treated with 5 '-aza. The increase in $\mathrm{PGE}_{2}$ production and COX-2 expression induced by $5^{\prime}$-aza, was similar (Fig. 1B and D).
COX-2 expression is highly regulated via both transcriptional and post-transcriptional mechanisms, depending on its activator and the cell type $(31,32)$. To verify the 5'-aza-induced COX-2 expression at the mRNA level, we treated the HT1080 cells with 5'-aza. RNA was extracted from the cells, and COX-2 mRNA levels were detected using RT-PCR. COX-2 expression increased in a dose- and time-dependent manner in cells treated with 5'-aza (Fig. 2). To correct differences in loading, the signal density of each COX-2 band was divided by the signal density of the GAPDH band (Fig. 2).

Several studies have shown the involvement of the PI3K/ Akt and ERK-1/2 pathways in the regulation of COX-2 expression and $\mathrm{PGE}_{2}$ synthesis $(33,34)$.

In this study, we found that 5'-aza phosphorylated ERK-1/2 and Akt. This observation was evident within $1 \mathrm{~h}$ of treatment 
A

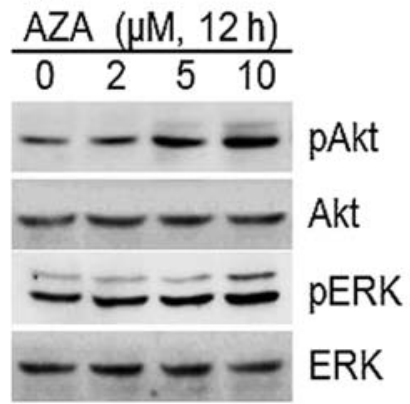

B

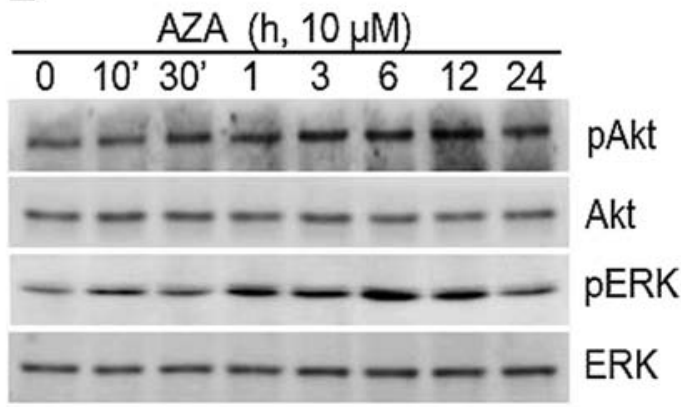

Figure 3. Treatment of 5'-aza activates the PI3K/Akt and ERK1/2 pathways. (A) Chondrocytes were treated with and without various concentrations of 5'-aza for $12 \mathrm{~h}$. (B) Chondrocytes were treated with and without $10 \mu \mathrm{M}$ 5'-aza for the indicated time periods. (A and B) Activation of pAkt, Akt, pERK, and ERK was analyzed using western blot analysis. Actin was used as a loading control.

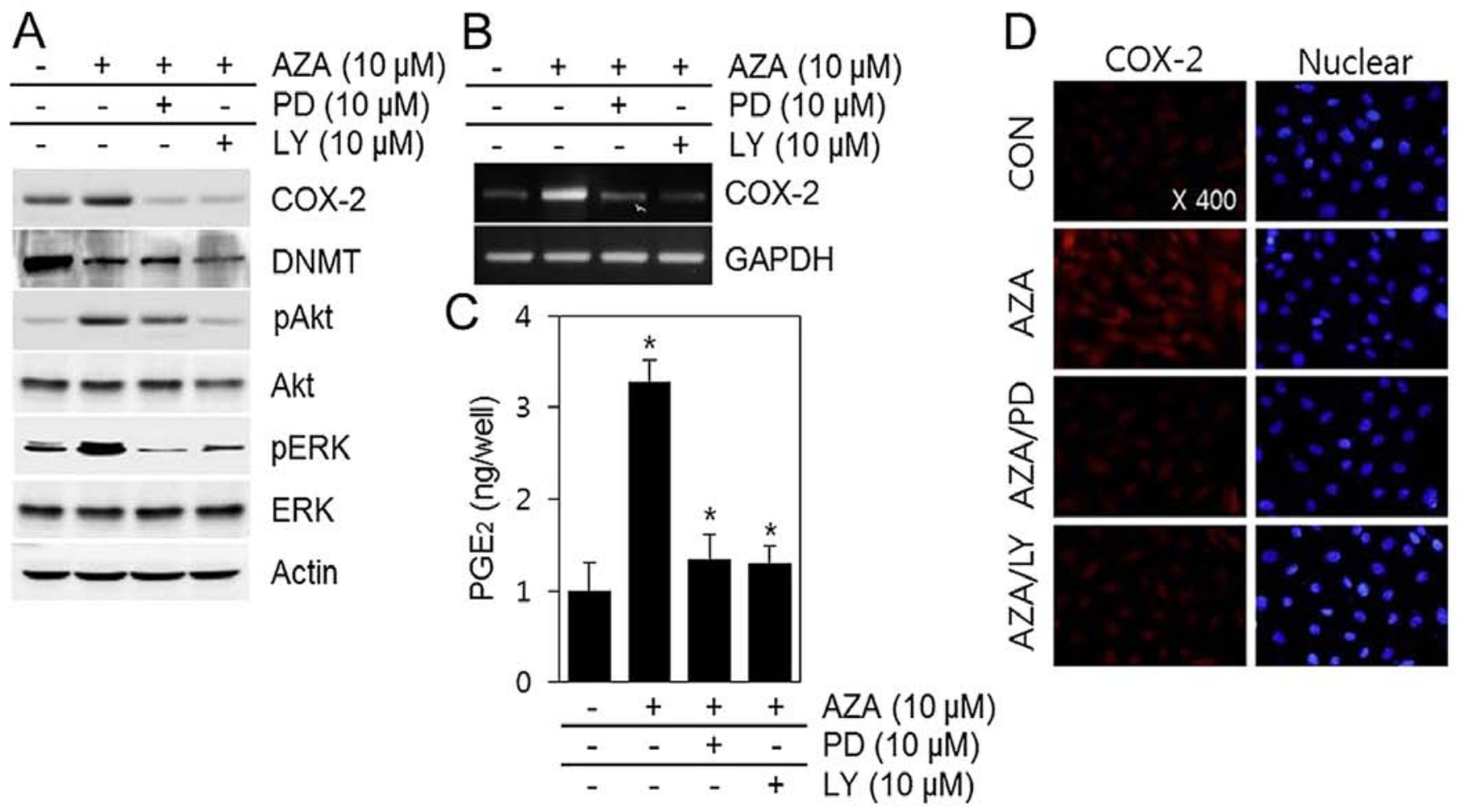

Figure 4. Inhibition of PI3K/Akt and ERK1/2 pathways prevents COX-2 expression and $\mathrm{PGE}_{2}$ production induced by 5'-aza. Chondrocytes were treated with and without $10 \mu \mathrm{M}$ 5'-aza in the absence and presence of $10 \mu \mathrm{M}$ PD98059 (PD) and $10 \mu \mathrm{M}$ LY294002 (LY). (A) Expression of COX-2, DNMT-1, pAkt, Akt, pERK, ERK and actin was detected using western blot analysis. Actin was used as a loading control. (B) The expression level of COX-2 was determined using RT-PCR. GAPDH was used as a loading control. (C) Secreted PGE $_{2}$ was quantified using the PGE $_{2}$ assay. (D) The expression of COX-2 was determined using immunofluorescence staining. The nuclei of cells were stained with 4'-6-diamidino-2-phenylindole (DAPI). The results represent three independent experiments. The data represent three similar experiments.
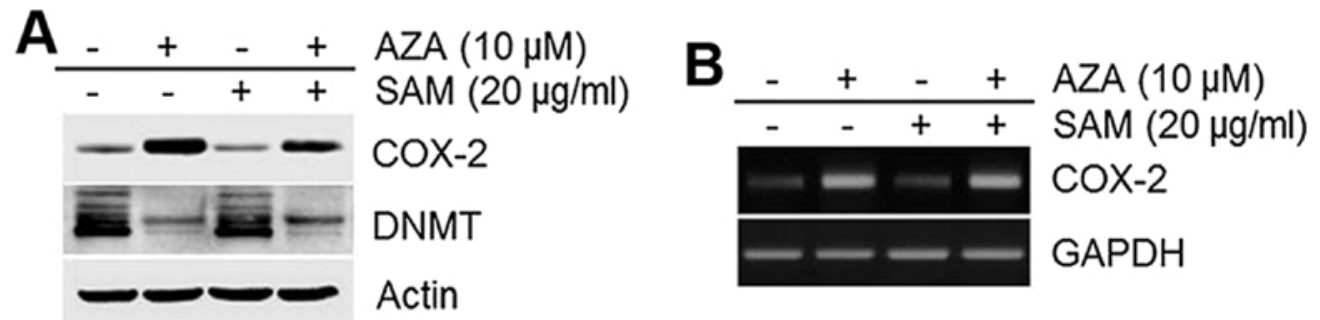

Figure 5. SAM inhibits 5'-aza-induced COX-2 expression. (A and B) Chondrocytes were treated with and without $10 \mu \mathrm{M} 5$ '-aza in the absence and presence of $20 \mu \mathrm{g} / \mathrm{ml}$ SAM. (A) Expression of COX-2, DNMT-1, and actin was detected using western blot analysis. Actin was used as a loading control. (B) The expression level of COX-2 was determined using RT-PCR. GAPDH was used as a loading control. The data represent three similar experiments. 
with phosphorylation levels reaching a maximum at $12 \mathrm{~h}$, and then decreasing (Fig. 3B). The total ERK-1/2 and Akt remained consistent through the duration of the experiments (Fig. 3).

To determine whether ERK-1/2 and PI3K/Akt are involved in 5'-aza-induced COX-2 expression and $\mathrm{PGE}_{2}$ synthesis, cells were treated with the ERK-1/2 inhibitor, PD 98059, and the PI3K/Akt inhibitor LY 294002 (Fig. 4).

Pre-treatment with PD 98059 or LY 294002 followed by stimulation with 5'-aza resulted in inhibition of 5'-azainduced effects on COX-2 mRNA expression and protein levels (Fig. 4A and B), and $\mathrm{PGE}_{2}$ synthesis (Fig. 4C). Immunofluorescence microscopy further indicated that treatment with 5'-aza dramatically increased COX-2 expression, but these effects were inhibited by treatment with PD 98059 and LY 294002 (Fig. 4D). Taken together, these results indicate that the ERK-1/2 and Akt pathways participate in the 5'-azainduced increase in COX-2 expression and $\mathrm{PGE}_{2}$ production (Fig. 4).

SAM is a methyl donor and an inhibitor of DNA methylation (35). We therefore examined and observed that SAM could inhibit the 5'-aza-induced COX-2 expression (Fig. 5A). Similar to COX-2 protein expression levels, COX-2 mRNA levels were also altered by SAM (Fig. 5B). These data demonstrate that COX-2 expression induced by 5'-aza is regulated by alterations in DNA methylation (Fig. 5).

\section{Discussion}

COX-2 is transcriptionally modulated in normal tissues by various factors including pro-inflammatory cytokines, tumor necrosis factor (TNF)- $\alpha$ (36), interleukin (IL)-1 $\beta$ (37), interferon (IFN) $-\gamma$ (38), and bacterial endotoxin (36).

Overexpression of COX-2 promotes cell growth, but at the same time leads to cell cycle arrest in diverse cell types $(39,40)$. In other words, the upregulated COX-2 expression may inhibit proliferation in the short-term, but ultimately allows cancer growth in the long-term. $\mathrm{PGE}_{2}$ is a major metabolite derived from arachidonic acid and its production is mediated by the action of COX-2. $\mathrm{PGE}_{2}$ inhibits cell growth in melanocytes (41), gastric cancer cells (42), colonic epithelial cells (43), and neuroblastoma cells (44).

In contrast, it has been reported that increased levels of $\mathrm{PGE}_{2}$ accelerates cell motility, alters morphology (45), and has growth-promoting activity via the epidermal growth factor (EGF) receptor (46).

Therefore, increased COX-2 expression and upregulated $\mathrm{PGE}_{2}$ production lead to various responses in carcinogenesis. Treatment with COX-2 inhibitors is known to reduce proliferation and cause apoptosis of cancers, but our previous results indicate that there is no relationship between COX-2 expression and proliferation of HT1080 cells (47). Although various studies on $\mathrm{COX}-2$ regulation are available, the molecular basis of COX-2 expression in cancer has not been established yet.

DNA methylation is an epigenetic mechanism of gene silencing, with no effects on chromatin structure (48). Global hypomethylation at repetitive sequences causes genomic instability. Aberrant hypomethylation of $\mathrm{CpG}$ islands in promoter region of a gene has been implicated in the transcriptional silencing of various genes in carcinogenesis (48).
Studies have indicated that $\mathrm{COX}-2$ promoter methylation may be an additional regulator of COX-2 expression in some cancer cell lines $(29,49)$.

In this study, we therefore examined whether COX-2 expression in human HT1080 fibrosarcoma cells is regulated through DNA methylation upon treatment with 5'-aza. We demonstrated that COX-2 expression and $\mathrm{PGE}_{2}$ production were regulated by the methylation status of the COX-2 promoter. Although overexpression of COX-2 has been observed in many cancers, concomitant increases in COX-2 expression may not be detected in HT1080 cells. However, after treatment with 5'-aza, increased COX-2 expression became detectable, consistent with the increased COX-2 mRNA levels (Figs. 1 and 2).

These findings suggest that methylation of the COX-2 promoter may be associated with transcriptional downregulation of the gene. We also examined the possibility that the opposing effects of DNA demethylation might be addressed by combining a DNA-demethylating agent with a DNA-methylating agent. SAM is synthesized in humans from the methyl donors present in the diet, and is a natural compound that is a cofactor of methylation reactions in vivo. We therefore tested whether SAM antagonizes the effect of 5'-aza (Fig. 5). We demonstrated that SAM inhibits the global hypomethylation caused by 5'-aza and antagonizes the effect of 5'-aza on COX-2 expression.

Promoter hypomethylation by 5'-aza upregulated COX-2 expression and $\mathrm{PGE}_{2}$ production (Figs. 1 and 2), while hypermethylation by SAM resulted in the opposite effect (Fig. 5).

Many reports indicate that mitogen-activated protein kinase (MAPK) and PI3K/Akt pathways are involved in regulating COX-2 expression and $\mathrm{PGE}_{2}$ production $(50,51)$. We assessed the role of MAPKs and PI3K activation in 5'-aza-induced COX-2 expression and $\mathrm{PGE}_{2}$ production (Figs. 3 and 4). 5'-aza activated ERK-1/2 and Akt, but not p38 and c-Jun N-terminal kinase (JNK) in HT1080 cells (data not shown). Therefore, another major finding of our study is that 5'-aza activates the ERK-1/2 and PI3K/Akt pathways (Fig. 3).

In conclusion, our data suggest that the expression of COX-2 in HT1080 cells is regulated by DNA methylation status, and these effects are regulated by ERK-1/2 and PI3K/ Akt pathways.

\section{Acknowledgements}

This study was supported by a grant from the National Research Foundation of Korea(NRF)(MEST)(NRF-2012R1A1A2043276 and 2014R1A1A3049653) and the Korean Health Technology R\&D Project, Ministry of Health and Welfare, Republic of Korea (A120960-1201-0000300).

\section{References}

1. Papagelopoulos PJ, Galanis E, Frassica FJ, Sim FH, Larson DR and Wold LE: Primary fibrosarcoma of bone. outcome after primary surgical treatment. Clin Orthop Relat Res 373: 88-103, 2000.

2. Baylin SB and Jones PA: A decade of exploring the cancer epigenome - biological and translational implications. Nat Rev Cancer 11: 726-734, 2011.

3. Szyf M: The role of DNA methyltransferase 1 in growth control. Front Biosci 6: D599-D609, 2001. 
4. Stresemann C, Bokelmann I, Mahlknecht U and Lyko F: Azacytidine causes complex DNA methylation responses in myeloid leukemia. Mol Cancer Ther 7: 2998-3005, 2008.

5. Voso MT, Breccia M, Lunghi M, Poloni A, Niscola P, Finelli C, Bari A, Musto P, Zambello R, Fianchi L, et al: Rapid loss of response after withdrawal of treatment with azacitidine: A case series in patients with higher-risk myelodysplastic syndromes or chronic myelomonocytic leukemia. Eur J Haematol 90: 345-348, 2013.

6. Silverman LR, Fenaux P, Mufti GJ, Santini V, HellströmLindberg E, Gattermann N, Sanz G, List AF, Gore SD and Seymour JF: Continued azacitidine therapy beyond time of first response improves quality of response in patients with higherrisk myelodysplastic syndromes. Cancer 117: 2697-2702, 2011.

7. Kaminskas E, Farrell A, Abraham S, Baird A, Hsieh LS, Lee SL, Leighton JK, Patel H, Rahman A, Sridhara R, et al: Approval summary: Azacitidine for treatment of myelodysplastic syndrome subtypes. Clin Cancer Res 11: 3604-3608, 2005.

8. Feinberg AP, Gehrke CW, Kuo KC and Ehrlich M: Reduced genomic 5-methylcytosine content in human colonic neoplasia. Cancer Res 48: 1159-1161, 1988.

9. Shteper PJ, Zcharia E, Ashhab Y, Peretz T, Vlodavsky I and Ben-Yehuda D: Role of promoter methylation in regulation of the mammalian heparanase gene. Oncogene 22: 7737-7749, 2003.

10. Wu KK: Cyclooxygenase 2 induction: Molecular mechanism and pathophysiologic roles. J Lab Clin Med 128: 242-245, 1996.

11. Bauer AK, Dwyer-Nield LD and Malkinson AM: High cyclooxygenase $1(\mathrm{COX}-1)$ and cyclooxygenase $2(\mathrm{COX}-2)$ contents in mouse lung tumors. Carcinogenesis 21: 543-550, 2000.

12. Nurmi JT, Puolakkainen PA and Rautonen NE: Intron 1 retaining cyclooxygenase 1 splice variant is induced by osmotic stress in human intestinal epithelial cells. Prostaglandins Leukot Essent Fatty Acids 73: 343-350, 2005.

13. Chell S, Kaidi A, Williams AC and Paraskeva C: Mediators of PGE2 synthesis and signalling downstream of COX-2 represent potential targets for the prevention/treatment of colorectal cancer. Biochim Biophys Acta 1766: 104-119, 2006.

14. Prescott SM and Fitzpatrick FA: Cyclooxygenase-2 and carcinogenesis. Biochim Biophys Acta 1470: M69-M78, 2000.

15. Hanahan D and Weinberg RA: Hallmarks of cancer: The next generation. Cell 144: 646-674, 2011.

16. Tang $X$, Sun YJ, Half E, Kuo MT and Sinicrope F: Cyclooxygenase-2 overexpression inhibits death receptor 5 expression and confers resistance to tumor necrosis factorrelated apoptosis-inducing ligand-induced apoptosis in human colon cancer cells. Cancer Res 62: 4903-4908, 2002.

17. Totzke G, Schulze-Osthoff K and Janicke RU: Cyclooxygenase-2 (COX-2) inhibitors sensitize tumor cells specifically to death receptor-induced apoptosis independently of COX-2 inhibition. Oncogene 22: 8021-8030, 2003.

18. Pockaj BA, Basu GD, Pathangey LB, Gray RJ, Hernandez JL, Gendler SJ and Mukherjee P: Reduced T-cell and dendritic cell function is related to cyclooxygenase-2 overexpression and prostaglandin E2 secretion in patients with breast cancer. Ann Surg Oncol 11: 328-339, 2004.

19. Castellone MD, Teramoto H, Williams BO, Druey KM and Gutkind JS: Prostaglandin E2 promotes colon cancer cell growth through a gs-axin-beta-catenin signaling axis. Science 310: 1504-1510, 2005.

20. Kinugasa Y, Hatori M, Ito H, Kurihara Y, Ito D and Nagumo M: Inhibition of cyclooxygenase-2 suppresses invasiveness of oral squamous cell carcinoma cell lines via down-regulation of matrix metalloproteinase-2 and CD44. Clin Exp Metastasis 21: 737-745, 2005.

21. Gallo O, Franchi A, Magnelli L, Sardi I, Vannacci A, Boddit V, Chiarugi V and Masini E: Cyclooxygenase-2 pathway correlates with VEGF expression in head and neck cancer. implications for tumor angiogenesis and metastasis. Neoplasia 3: 53-61, 2001.

22. Masferrer JL, Leahy KM, Koki AT, Zweifel BS, Settle SL, Woerner BM, Edwards DA, Flickinger AG, Moore RJ and Seibert K: Antiangiogenic and antitumor activities of cyclooxygenase-2 inhibitors. Cancer Res 60: 1306-1311, 2000

23. Tsujii M, Kawano S and DuBois RN: Cyclooxygenase-2 expression in human colon cancer cells increases metastatic potential. Proc Natl Acad Sci USA 94: 3336-3340, 1997

24. Byun JH, Lee MA, Roh SY, Shim BY, Hong SH, Ko YH, Ko SJ, Woo IS, Kang JH, Hong YS, et al: Association between cyclooxygenase- 2 and matrix metalloproteinase-2 expression in non-small cell lung cancer. Jpn J Clin Oncol 36: 263-268, 2006.
25. Eberhart CE, Coffey RJ, Radhika A, Giardiello FM, Ferrenbach S and DuBois RN: Up-regulation of cyclooxygenase 2 gene expression in human colorectal adenomas and adenocarcinomas. Gastroenterology 107: 1183-1188, 1994.

26. Ristimaki A, Honkanen N, Jankala H, Sipponen $P$ and Harkonen M: Expression of cyclooxygenase-2 in human gastric carcinoma. Cancer Res 57: 1276-1280, 1997.

27. Wolff H, Saukkonen K, Anttila S, Karjalainen A, Vainio H and Ristimaki A: Expression of cyclooxygenase-2 in human lung carcinoma. Cancer Res 58: 4997-5001, 1998.

28. Liu XH and Rose DP: Differential expression and regulation of cyclooxygenase- 1 and -2 in two human breast cancer cell lines. Cancer Res 56: 5125-5127, 1996.

29. Toyota M, Shen L, Ohe-Toyota M, Hamilton SR, Sinicrope FA and Issa JP: Aberrant methylation of the cyclooxygenase $2 \mathrm{CpG}$ island in colorectal tumors. Cancer Res 60: 4044-4048, 2000.

30. Huang L, Zhang KL, Li H, Chen X-Y, Kong Q-Y, Sun Y, Gao X, Guan $\mathrm{H}-\mathrm{W}$ and Liu J: Infrequent COX-2 expression due to promoter hypermethylation in gastric cancers in Dalian, China. Hum Pathol 37: 1557-1567, 2006.

31. Ramsay RG, Ciznadija D, Vanevski M and Mantamadiotis T: Transcriptional regulation of cyclo-oxygenase expression: Three pillars of control. Int J Immunopathol Pharmacol 16: 59-67, 2003.

32. Tanabe $\mathrm{T}$ and Tohnai $\mathrm{N}$ : Cyclooxygenase isozymes and their gene structures and expression. Prostaglandins Other Lipid Mediat 68-69: 95-114, 2002.

33. St-Germain ME, Gagnon V, Mathieu I, Parent S and Asselin E: Akt regulates COX-2 mRNA and protein expression in mutatedPTEN human endometrial cancer cells. Int J Oncol 24: 1311-1324, 2004.

34. Takeda K, Kanekura T and Kanzaki T: Negative feedback regulation of phosphatidylinositol 3-kinase/akt pathway by overexpressed cyclooxygenase-2 in human epidermal cancer cells. J Dermatol 31: 516-523, 2004.

35. Detich N, Hamm S, Just G, Knox JD and Szyf M: The methyl donor S-adenosylmethionine inhibits active demethylation of DNA: A candidate novel mechanism for the pharmacological effects of S-adenosylmethionine. J Biol Chem 278: 20812-20820, 2003.

36. Minghetti L, Walsh DT, Levi G and Perry VH: In vivo expression of cyclooxygenase- 2 in rat brain following intraparenchymal injection of bacterial endotoxin and inflammatory cytokines. J Neuropathol Exp Neurol 58: 1184-1191, 1999.

37. Giordano S, Maffe A, Williams TA, Artigiani S, Gual P, Bardelli A, Basilico C, Michieli P and Comoglio PM: Different point mutations in the met oncogene elicit distinct biological properties. FASEB J 14: 399-406, 2000.

38. Matsuura H, Sakaue M, Subbaramaiah K, Kamitani H, Eling TE, Dannenberg AJ, Tanabe T, Inoue H, Arata J and Jetten AM: Regulation of cyclooxygenase-2 by interferon gamma and transforming growth factor alpha in normal human epidermal keratinocytes and squamous carcinoma cells. role of mitogenactivated protein kinases. J Biol Chem 274: 29138-29148, 1999.

39. DuBois RN, Shao J, Tsujii M, Sheng H and Beauchamp RD: G1 delay in cells overexpressing prostaglandin endoperoxide synthase-2. Cancer Res 56: 733-737, 1996.

40. Trifan OC, Smith RM, Thompson BD and Hla T: Overexpression of cyclooxygenase-2 induces cell cycle arrest. evidence for a prostaglandin-independent mechanism. J Biol Chem 274: 34141-34147, 1999.

41. Santoro MG, Philpott GW and Jaffe BM: Inhibition of tumour growth in vivo and in vitro by prostaglandin E. Nature 263: 777-779, 1976

42. Shimakura S and Boland CR: Eicosanoid production by the human gastric cancer cell line AGS and its relation to cell growth. Cancer Res 52: 1744-1749, 1992.

43. DeRubertis FR, Craven PA and Saito R: 16,16-dimethyl prostaglandin E2 suppresses the increases in the proliferative activity of rat colonic epithelium induced by indomethacin and aspirin. Gastroenterology 89: 1054-1063, 1985.

44. Prasad KN: Morphological differentiation induced by prostaglandin in mouse neuroblastoma cells in culture. Nat New Biol 236: 49-52, 1972.

45. Sheng H, Shao J, Washington MK and DuBois RN: Prostaglandin E2 increases growth and motility of colorectal carcinoma cells. J Biol Chem 276: 18075-18081, 2001.

46. Pai R, Soreghan B, Szabo IL, Pavelka M, Baatar D and Tarnawski AS: Prostaglandin E2 transactivates EGF receptor: A novel mechanism for promoting colon cancer growth and gastrointestinal hypertrophy. Nat Med 8: 289-293, 2002. 
47. Gweon EJ, Jung JC and Kim SJ: Luteolin induces inhibition of cell proliferation and COX-2 expression via ERK pathway in human fibrosarcoma HT1080. Cancer Prev Res (Phila) 17: 218-225, 2012.

48. Rashid A and Issa JP: CpG island methylation in gastroenterologic neoplasia: A maturing field. Gastroenterology 127: 1578-1588, 2004.

49. Akhtar M, Cheng Y, Magno RM, Ashktorab H, Smoot DT, Meltzer SJ and Wilson KT: Promoter methylation regulates helicobacter pylori-stimulated cyclooxygenase- 2 expression in gastric epithelial cells. Cancer Res 61: 2399-2403, 2001.
50. Mercau ME, Astort F, Giordanino EF, Martinez Calejman C, Sanchez R, Caldareri L, Repetto EM, Coso OA and Cymeryng CB: Involvement of PI3K/akt and p38 MAPK in the induction of COX-2 expression by bacterial lipopolysaccharide in murine adrenocortical cells. Mol Cell Endocrinol 384: 43-51, 2014.

51. Yu SM and Kim SJ: Production of reactive oxygen species by withaferin A causes loss of type collagen expression and COX-2 expression through the PI3K/akt, p38, and JNK pathways in rabbit articular chondrocytes. Exp Cell Res 319: 2822-2834, 2013. 